\title{
Canadian Allergy, Asthma and Immunology Foundation
}

The Canadian Allergy, Asthma and Immunology Foundation (CAAIF) raises monies to fund research and teaching in allergy, asthma, and immunology. We thank all those who have contributed to CAAIF. We have also been fortunate to have enlisted the following partners to help fund fellowships and research awards: Anaphylaxis Canada, Bayer, Canadian Institutes of Health Research, GlaxoSmithKline, and Merck Frosst. We thank them for their ongoing support. We are proud to announce the winners of this year's awards.

The First Annual Clinical Fellowship was awarded to Greg Appelt;

The GlaxoSmithKline Fellowship in the field of Allergy and Clinical Immunology was awarded to Dr. Joel Liem for his project entitled "Is there an association between prematurity/birthweight and asthma";

The First Annual Anaphylaxis Award to Encourage Anaphylaxis Research in Canada was awarded to Dr. Kent HayGlass for his project entitled "Peanut allergy vs. clinical tolerance in young adults";

The Research Institute of Fragrance Management awarded Dr. Karen Binkley a fellowship for her project entitled "Genetics and stress responses in idiopathic environmental intolerance and other unexplained multisystem disorders".

Many thanks to all for your support of the Foundation!

Zave Chad, MD

Chair, CAAIF

\section{Editorial}

\section{First Issue of Allergy, Asthma, and Clinical Immunology}

We would like to welcome you as readers, to the first issue of Allergy, Asthma, and Clinical Immunology, the Journal of the Canadian Society of Allergy and Clinical Immunology.

To reach this point has taken a great deal of patient effort by the Members of the Board of the Society, by Louise Tremblay and the Executive Office, and by the Publishers, BC Decker, especially John Birkby and Carol Hunkeler.

Most of the work for this issue is the result of Carol and Keith Payton's successful collaboration. A special thanks Keith who stepped back into the Co-Editor-in-Chief position.

In April, Keith had suggested that it might be more efficient if the Editorial Office was located at a single site and as a result, Wade Watson will take over as Co-Editor-in-Chief here in Winnipeg, where mosquitoes and cold ensure dedicated service to the Journal 48 weeks of the year.

This issue contains excellent articles on rhinosinusitis and the treatment of asthma, as well as the programme for the fall meeting of the Society, which hopefully as many as possible of you will attend.
Deserving of comment is that one of the papers is by John Toogood. As you all are aware, John has had a long and extremely illustrious career in allergy and clinical immunology in Canada. In 1960, Dr. Toogood pioneered the introduction of inhaled steroid therapy for chronic asthma. Subsequently, his years of scientific research on the treatment of asthma have received national and international scientific recognition. John has published extensively in the fields of asthma, allergy, clinical trials methodology, and medical history. Since his retirement from the University of Western Ontario in 1993 at the age of 70, he has published 30 scientific articles and continues to be a consultant to the pharmaceutical industry and government on matters related to drug therapy for asthma. He is an example to us all, which if followed predicts a great future for our new Journal.

Richard Warrington, $\mathrm{MB}, \mathrm{BS}, \mathrm{PhD}, \mathrm{FRCPC}$ 